Psychological Medicine, 1988, 18, 535-543

Printed in Great Britain

\title{
EDITORIAL
}

\section{Toxic interactions between lithium and non-steroidal anti-inflammatory drugs ${ }^{1}$}

Affective disorder and arthritis are both common conditions, and drugs form the mainstay of treatment for both illnesses. Despite the large variety of agents used to treat both disorders, toxic interactions between psychotropic and the anti-rheumatic drugs seem uncommon. One combination that has recently attracted some attention is lithium toxicity precipitated by certain non-steroidal anti-inflammatory drugs (NSAIDs).

Approximately one million people in the UK suffer from rheumatoid arthritis, and probably a further three million have osteo-arthritis, a substantial proportion of these patients requiring NSAIDs. In the USA in 1982 there were 19 million prescriptions for ibuprofen (Overview, 1986). McCreadie \& Morrison (1985) found that $0.77 / 100000$ of the population were taking lithium which gives a figure of about 40000 patients taking lithium in the UK. Thus, quite large numbers of people could be taking lithium and NSAIDs together.

This review covers the current literature on lithium NSAID interaction and addresses the question as to possible underlying mechanisms. So far only five cases of lithium toxicity, secondary to the addition of a NSAID, have been reported. Three of these were from the UK, one from France and one from the USA; they occurred over a seven-year period, indicating that these instances are rather rare. There have also been several studies of the effects of NSAIDs on plasma lithium levels and lithium excretion in normal human volunteer subjects. As it is thought that NSAIDs act by inhibiting prostaglandin synthesis, we examine the possibility that prostaglandins may play a role in the excretion of the lithium ion and particularly the role prostaglandins may have in drug-induced lithium nephrotoxicity.

This editorial will cover the following areas.

(1) The published reports of cases where toxic interactions have been reported.

(2) Human studies where volunteers stabilized on lithium have been given various NSAIDs, and both lithium levels and lithium clearance have been measured.

(3) Renal function and other factors which may have affected serum lithium levels.

(4) Renal function and prostaglandins.

(5) The possible role of prostaglandins in psychiatric disorder.

(6) Animal and in vitro studies on the effects of lithium, psychotropic drugs, and NSAIDs on prostaglandin synthesis.

(7) Conclusions.

\section{CASE HISTORIES}

A total of five cases with a raised serum lithium resulting in a clinical episode of lithium toxicity have been reported. These are summarized in Table 1. Three patients with manic depressive psychosis (Imbs et al. 1978; Herschberg \& Sierles, 1983; Walbridge \& Bazire, 1985), one with severe intractable depression (Nadarajah \& Stein, 1985), and one with recurrent unipolar depressive illness (Kerry et al. 1983) showed such classic signs of lithium toxicity as confusion, unsteadiness, coarse tremor, restlessness, impaired attention, poor concentration and incomprehensible speech when a NSAID was added to their existing treatment regime. In every instance the signs of toxicity were temporary and disappeared after the NSAID was discontinued. Patient No. 2 (Kerry et al. 1983) had been physically and mentally well for nine-and-a-half years, maintained only on

\footnotetext{
1 Address for correspondence: Dr. G. S. Stein, Farnborough Hospital, Farnborough Common, Orpington, Kent, BR6 8ND.
} 
lithium. After a diagnosis of arthritis was made, Piroxicam was introduced, and in the next year she had three admissions with classical signs of lithium toxicity; serum levels were within the toxic range each time. It should be noted that on one occasion she had stopped taking lithium prior to admission. Patient No. 4 (Nadarajah \& Stein, 1985) had intractable depression which had failed to respond to ECT, several antidepressants and a subcaudate tractotomy. He was maintained on clomipramine, and the addition of lithium was thought to have given some benefit. After developing arthritis, he was placed on Piroxicam by his general practitioner. He gradually took to his bed, but this was thought to be a consequence of his depression. However, once he stopped eating and drinking he was admitted to hospital and a diagnosis of lithium toxicity was confirmed by his raised serum level of 2.4 mequiv./l (see Table 1). As with the previous patient, although he had stopped

Table 1. Changes in serum lithium concentration in human volunteer subjects after taking lithium and NSAIDs, and case reports of lithium toxicity, following the administration of a NSAID

\begin{tabular}{|c|c|c|c|c|c|c|c|c|}
\hline \multirow[b]{2}{*}{ Author } & \multicolumn{3}{|c|}{ Subjects } & \multirow[b]{2}{*}{ Anti-Rh. drug } & \multirow{2}{*}{$\begin{array}{l}\text { Dose of } \\
\text { Anti-Rhu. } \\
\text { drug (mg) }\end{array}$} & \multirow[b]{2}{*}{$\begin{array}{c}\text { Lithium } \\
\text { dosage }(\mathrm{mg})\end{array}$} & \multirow{2}{*}{$\begin{array}{l}\text { Baseline } \\
\text { serum } \\
\text { lithium } \\
\text { mequiv./I }\end{array}$} & \multirow[b]{2}{*}{$\begin{array}{l}\text { Serum lithium } \\
\text { after anti-Rh } \\
\text { drug mequiv./I }\end{array}$} \\
\hline & $\begin{array}{c}\text { Age } \\
\text { and status }\end{array}$ & Sex & $N$ & & & & & \\
\hline Imbs et al. (1978) & 53 -pattent & $\mathbf{F}$ & 1 & Phenylbutazone & 750 & 1000 & 0.70 & 1.44 \\
\hline Hierschberg \& Sierles, (1983) & 56 -patient & $\mathbf{M}$ & 1 & Indomethacin & 200 & 900 & $0.80-1.40$ & $3 \cdot 50$ \\
\hline Kerry et al. (1983) & 56 - patient & $\mathbf{F}$ & 1 & Piroxicam & 20 & Not stated & $0.8-1 \cdot 40$ & 2.4 \\
\hline \multirow[t]{2}{*}{ Walbridge \& Bazire (1985) } & 65 - patient & $\mathbf{F}$ & $\mathbf{I}$ & Piroxicam & 20 & 1000 & $0.5-0.8$ & $1 \cdot 01-1 \cdot 18$ \\
\hline & & & & Ibuprofen & 600 & 1000 & $0.5-0.8$ & $0.5-0.8$ \\
\hline Nadarajah \& Stein (1985) & 63 -patient & $\mathbf{M}$ & 1 & Piroxicam & 40 & 1000 & $0.6-0.9$ & $2 \cdot 4$ \\
\hline Frohlich et al. (1979) & Volunteers & - & 4 & Indomethacin & 150 & Variable & 0.95 & 1.5 \\
\hline Reimann et al. (1983) & Volunteers & - & 10 & Indomethacin & 150 & Variable & $0.68 \pm 0.03$ & $\begin{array}{c}0.84 \pm 0.06 \\
P<0.01\end{array}$ \\
\hline Reimann et al. (1983) & Volunteers & - & 3 & Indomethacin & 150 & Variable & 0.89 & 1.43 \\
\hline Reimann \& Frolich (1981) & Volunteers & - & 5 & Diclofenac & 150 & 660 & 0.63 & 0.82 \\
\hline Ragheb et al. (1980) & Volunteers & - & 3 & Ibuprofen & $\begin{array}{l}2400 \\
1200\end{array}$ & Variable & 0.80 & $1.0 \mathrm{mg}$ \\
\hline Walbridge \& Bazire (1985) & 64 -patient & $\mathbf{F}$ & 1 & Ibuprofen & Not stated & Not stated & \multicolumn{2}{|c|}{$\begin{array}{l}\text { 'Change' } \\
\text { 'No change' }\end{array}$} \\
\hline Reimann et al. (1983) & Volunteers & - & 10 & Aspirin & 4000 & Variable & $0.63 \pm 0.03$ & $\begin{array}{c}0.60 \pm 0.04 \\
\text { (NS) }\end{array}$ \\
\hline Bendz \& Feinberg (1984) & Volunteer & - & 1 & Aspirin & 3900 & 330 & 0.41 & 0.54 \\
\hline
\end{tabular}

\begin{tabular}{|c|c|c|c|c|c|c|}
\hline \multirow[b]{2}{*}{ Author } & \multicolumn{3}{|c|}{ Subjects } & \multirow[b]{2}{*}{$\begin{array}{l}\text { Speed } \\
\text { of change }\end{array}$} & \multirow[b]{2}{*}{ Concomitant disease } & \multirow[b]{2}{*}{ Other medication } \\
\hline & $\begin{array}{c}\text { Age } \\
\text { and status }\end{array}$ & Sex & $N$ & & & \\
\hline Imbs et al. (1987) & 53 - patient & $\mathrm{F}$ & 1 & 10 days & $\begin{array}{l}\text { Cardiac } \\
\text { Fracture } \\
\text { Phlebitics }\end{array}$ & $\begin{array}{l}\text { Isosobride nitrate } \\
\text { Spironolactone } \\
\text { Heparin } \\
\text { Viloxazine } \\
\text { Chlorazepate }\end{array}$ \\
\hline Hierschberg \& Sierles, (1983) & 56 - patient & $\mathbf{M}$ & 1 & 9 days & $\begin{array}{l}\text { Alcoholism. Liver damage } \\
\text { Previous myocardial infarct } \\
\text { Arterio-sclerotic heart disease }\end{array}$ & $\begin{array}{l}\text { Aminophylline } \\
\text { Zomepirac* }\end{array}$ \\
\hline Kerry et al. (1983) & 56 - patient & $\mathrm{F}$ & 1 & Not stated & Arthritis & Nil \\
\hline Walbridge \& Bazıre (1985) & 65 -patient & $\mathbf{F}$ & $i$ & $\begin{array}{l}\text { Not stated } \\
\text { N/A }\end{array}$ & Osteo-arthritis & Nil \\
\hline Nadarajah \& Stein (1985) & 63 - patient & $\mathbf{M}$ & 1 & 'Months' & $\begin{array}{l}\text { Previous subcaudate tractotomy } \\
\text { Osteo-arthritis }\end{array}$ & $\mathrm{Nil}$ \\
\hline Frohlich et al. (1979) & Volunteers & - & 4 & 5 days & & \\
\hline Reimann et al. (1983) & Volunteers & - & 10 & 7 days & & \\
\hline Reimann et al. (1983) & Volunteers & - & 3 & 6 days & & Nil \\
\hline Reimann \& Frolich (1981) & Volunteers & - & 5 & 7 days & Normal healthy volunteers/ & \\
\hline Ragheb et al. (1980) & Volunteers & - & 3 & 7 days & no physical disorders & \\
\hline Walbridge \& Bazire (1985) & 64 - patient & $\mathrm{F}$ & 1 & 7 months & & \\
\hline Reimann et al. (1983) & Volunteers & - & 10 & 7 days & & \\
\hline Bendz \& Feinberg (1984) & Volunteer & $\mathbf{M}$ & 1 & 7 days & & \\
\hline
\end{tabular}

* A NSAID which has been withdrawn. 
taking lithium, his plasma lithium level remained persistently high for a further three days: only when Piroxicam was stopped did the lithium levels fall to zero, indicating that the Piroxicam had delayed lithium excretion. The final patient (Wallbridge \& Bazire, 1985) developed lithium toxicity on two occasions when given concomitant Piroxicam, but never with ibuprofen (see Table 1).

\section{HUMAN STUDIES}

Systematic evaluation of the interaction between lithium and NSAIDs in human volunteers appears to have been prompted by a chance observation made in one patient who had lithium-induced polyuria which responded to indomethacin (Leftwich et al. 1977). In metabolic unit studies, volunteers receiving lithium were given a constant sodium intake and lithium levels were checked until they failed to show a daily fluctuation greater than 0.1 mequiv./1 before any experimental drug was administered. A placebo was given initially, followed by 7-10 days of an NSAID experimental drug, followed by a further week of placebo. Using this design (Ragheb et al. 1980; Reimann \& Frolich, 1981 ; Reimann et al. 1983), the effects of indomethacin, ibuprofen, diclofenac, and aspirin, on plasma lithium and renal lithium clearance were studied and the main findings appear to be as follows:

Indomethacin $50 \mathrm{mg}$ tds increased plasma lithium by $50 \%$ in three patients, and $30 \%$ in four volunteers, reducing renal lithium clearance by $30 \%$. Diclofenac led to a $26 \%$ increase in plasma lithium and a $23 \%$ decrease in lithium clearance. For ibuprofen, only weak and inconsistent effects were observed. Thus, one patient, who was taking ibuprofen $(2.4 \mathrm{~g}$ per day), developed nausea and drowsiness during the experimental period, but his plasma lithium level only rose from 0.80 to 1.00. The authors questioned whether his symptoms were due to lithium toxicity or side effects resulting from a rather high dose of ibuprofen. His plasma lithium showed no changes following $1 \cdot 2 \mathrm{~g}$ of ibuprofen. One patient developed lithium toxicity with Piroxicam but not with ibuprofen (Walbridge \& Bazire, 1985). Aspirin produced little or no change in plasma lithium levels evt.1. at a high dosage of $4 \mathrm{~g}$ /day. (Reimann et al. 1983). However, Bendz \& Feinberg (1984) reported a 43 year-old man who showed a significant rise in plasma lithium, from 0.41 to 0.54 mequiv./1 on being given aspirin. Reimann \& Frohlich (1984) questioned Bendz's findings, and suggested that they may have been an artefact caused by failure to strictly control sodium intake, as both sodium intake and sodium excretion can profoundly influence lithium excretion. The pattern of lithium-NSAID interaction in human volunteers thus resembles that for the toxic interactions in patients, with indomethacin but not aspirin or ibrufen, affecting serium lithium levels. Piroxicam has not yet been tested in human volunteers, but as it is a very potent prostaglandin synthesis inhibitor and results in clinical lithium toxicity, it would be of interest to examine its effects in volunteers on lithium levels.

\section{RENAL MECHANISMS AND OTHER FACTORS WHICH MAY HAVE AFFECTED LITHIUM LEVELS}

There are several other factors which independently can affect serum lithium levels and all of these must be considered when assessing a possible newly proposed mechanism of lithium toxicity. These include renal function, the state of hydration, properties of the preparation, gastric function, external temperature and other factors.

Impaired renal function is a major factor in the development of lithium toxicity. Thus in the largest published series of cases of lithium toxicity, 23 patients were reported (Hansen \& Amdisen, 1978), and of these 17 had renal insufficiency during the episode of lithium toxicity, with five patients failing to regain normal renal function on recovery. Renal biopsies revealed abnormalities in seven of these patients, suggesting the presence of a chronic nephropathy possibly induced by lithium. In three of the patients hypertonic dehydration was also thought to be a factor. The mechanism whereby renal damage predisposes to lithium toxicity is uncertain, and it may be that a combination of states of sodium depletion or water loss together with renal damage are required 
before toxicity develops. A further complicating factor is that some NSAIDs can cause structural damage. Thus, fenclofenac (Raftery et al. 1985) and fenoprofen (Kimberley et al. 1978; Wendland et al. 1980) can cause structural renal damage as well as a reduction in renal function. Piroxicam (Frais et al. 1983) and indomethacin (Brezin et al. 1979; Tan et al. 1979; Galler et al. 1981) may also produce renal insufficiency. Lithium produces a mild degree of tubular damage (Hansen et al. 1979), which may result in marked distal dysfunction and an impaired glomerular filtration rate (Walker et al. 1982). Lithium itself is reported to inhibit its own excretion. Renal lithium clearance is normally about $15-20 \mathrm{ml} /$ minute and this may be markedly reduced during an episode of lithium intoxication, with values of $5 \mathrm{ml} / \mathrm{minute}$ or less being documented (Haghfelt et al. 1971). This inhibiting effect of lithium on its own excretion may explain why toxicity develops so rapidly once the lithium level has risen beyond a critical point.

Two of the five cases in which lithium toxicity was reported also had severe medical illnesses where some degree of renal impairment might have been present prior to the administration of the NSAID. Thus, Shelley (1986) observed not only that renal function is most likely to be adversely affected by a NSAID if impairment is already present, but also that prostaglandins tend to become more active with deteriorating renal failure.

The other three cases of toxicity occurred with one particular NSAID, namely Piroxicam. This drug was developed with the specific aim of having a long half-life (36-48 hours) so that a single daily dose would give 24 hour pain relief and therefore cover the night (Wiseman \& Boyle, 1980; Vrhovac, 1984). Indomethacin and aspirin have much shorter half-lives and do not provide such a constant high degree of prostaglandin synthesis inhibition and pain relief. Even if these drugs are taken three times daily, there is low degree of prostaglandin inhibition at night. Possibly this could be why a long acting NSAID such as Piroxicam is rather more liable to result in lithium toxicity.

An alternative explanation for the development of lithium toxicity in these cases may be that they were simply dehydrated as a consequence of their not eating or drinking secondary to their depression, or because of some other incidental illness such as influenza. If this was the explanation, lithium levels would be expected to move in tandem with the degree of dehydration, as might be measured by the haemotocrit. More information on the state of hydration is available in two of the five cases. In the case of Hierschberg \& Sierles (1983) the patient had a haematocrit of $33.4 \%$, while his plasma lithium level was in the range of 0.8-1.4 mequiv./l. During his episode of lithium toxicity the plasma lithium rose to 3.5 mequiv./1 but the haemotocrit only rose to $35.6 \%$ and so simple dehydration cannot account for the dramatic rise in plasma lithium. In the case of Nadarajah \& Stein, the patient's packed cell volume was $44 \%$ on admission, and haemoglobin was $14.9 \mathrm{~g} / 100 \mathrm{ml}$ when the lithium level was 2.4 mequiv./1; however, one year later, while off lithium completely, his haemoglobin was 12.8 and the packed cell volume was $37 \%$, suggesting that some dehydration was present when he was admitted, but that it was insufficient to account for his abnormally high serum lithium level.

A host of other factors may also affect serum lithium levels and they should all be briefly considered when trying to assess a possible new causal mechanism for lithium toxicity.

First, there is inter-laboratory variability of measurement (Fry \& Marks, 1971) and split samples tested in different laboratories can vary by as much as 0.4 to 1.6 mequiv./l, even when a steady state has been reached (Weir, 1973). The preparation of lithium and its bio availability may also affect serum level. Thus, lithium carbonate can be taken as Camcolit or Priadel, the latter being a slow release form, which is said to produce steadier serum levels with less peaking. However, in several studies variable absorption with slow release preparations of lithium carbonate has been reported (Coppen et al. 1969; Caldwell et al. 1971; Tyrer et al. 1976), while in one meticulous study two sustained release preparations showed slow release in vitro, but not in vivo (Tyrer et al. 1976). Hot weather can cause excess sodium loss in sweat as well as decreased sodium intake due to anorexia and this too can result in increased serum lithium levels (Amdisen, 1980). Gastric emptying, and irregular food intake can also affect serum lithium (Crammer et al. 1974). The time interval between ingestion of the lithium and blood sampling may also make a crucial difference in 
the serum lithium level. Finally, non-compliance on the part of the patient may also be a factor in some individuals (Blackwell, 1976).

\section{RENAL FUNCTION AND PROSTAGLANDINS}

Lithium excretion is intimately linked to sodium excretion which in turn is regulated by renal prostaglandins (Stokes \& Kokko, 1977; Reimann et al. 1983). Thus NSAIDs, which act by inhibiting prostaglandin synthesis and reduce sodium excretion (Vrhovac, 1984), might be expected to have some influence on lithium excretion.

In human volunteers, indomethacin reduces glomerular filtration rate, plasma renin activity and, as a consequence, both sodium and water excretion are reduced (Donker et al. 1976). These effects are greater among sodium depleted subjects. Among volunteers taking lithium, indomethacin and diclofenac cause a 50\% reduction in prostaglandin E2 (PGE2) (Frolich et al. 1979; Reimann \& Frolich, 1981). However, as aspirin also causes a $70 \%$ reduction in PGE2 but does not lead to a decrease in lithium ion excretion (Reimann et al. 1983), PGE2, cannot be the prime prostaglandin mediator. Prostaglandin El (PGEl) has not yet been measured among subjects taking lithium who also take NSAIDs, but it may be of greater interest because it is a potent inhibitor of vasopressin. In lithium treated rats, Mtabaji et al. (1977) showed that water diuresis was insensitive to the effects of vasopressin infusions. However, this sensitivity was restored if Prostaglandin A2 (PGA2) was added to the vasopressin infusion. In the very low doses of PGA2 used there was no independent effect of PGA2 on diuresis.

Lithium can also inhibit the formation of cyclic AMP (Wang et al. 1974) in platelets. These investigators measured the effect of lithium on the ability of PGE1 with regard to stimulating the enzyme adenylcyclase. This can be measured by monitoring the production of cyclic AMP from labelled ATP in platelets. PGEl produces a large (32-fold) increase in cyclic AMP production, but the addition of a high concentration, i.e. $6 \mathrm{mmol}$ of lithium to the platelets inhibits this increase by $29 \%$. This effect is dose dependent, because when only one mmol of lithium was added the reduction in PGE1 induced cyclic AMP production was only $14 \%$. Lithium alone without PGE1 does not alter the basal synthesis of cyclic AMP. Cyclic AMP production was the same when concentrations of $1 \mathrm{mmol}$ and $6 \mathrm{mmol}$ of lithium were added to the incubation fluid. There was a greater degree of inhibition when the platelets with PGE1 were in contact with lithium for one hour, compared with being in contact for only two minutes.

\section{PSYCHIATRIC DISORDERS AND PROSTAGLANDINS}

A number of research workers have attempted to link prostaglandins directly with either schizophrenia or affective disorder, but so far convincing evidence of any causal link is lacking. Feldberg (1976) initially proposed that schizophrenia might be related to an increase in prostaglandin synthesis in certain areas of the brain. He likened the condition of catalepsy in the cat, to catatonia in schizophrenic patients and demonstrated that catelepsy could be induced by intra-cerebral injections of PGE1. Mtabaji et al. (1977), on somewhat scanty evidence, proposed that alcoholism might also be related to altered prostaglandin production. Withdrawal of alcohol results in a reduction of PGEl synthesis, while Rotrosen et al. (1980) have demonstrated that PGE1 reverses certain features of the alcohol withdrawal syndrome in alcohol dependent mice, particularly tremor, irritability and the frequency of convulsions.

Abdulla \& Hammadah (1975) studied the basal synthesis rate of PGE1 from its precursor in platelets. The rate of manufacture was the same in patients with affective disorder, schizophrenia and normal controls. However, high concentrations of ADP enhanced PGE1 synthesis in the platelets of the depressives and controls by $400-500 \%$, but this enhancement was not present in schizophrenics. In a study of 39 schizophrenics, who satisfied the Research Diagnostic Criteria, and matched controls, Rotrosen et al. (1980) found that the platelets from the control subjects had the highest values for PGEl induced, cyclic AMP accumulation, while medicated schizophrenics had 
lower rates, and neuroleptic free schizophrenics had the lowest accumulation rates. Kafka \& Van Kammen (1979) also found a reduction in PGEl induced cyclic AMP production in schizophrenics, but this could only be demonstrated for males and not for females. Recently, Kanof et al. (1986) also examined the effect of PGE1 on cyclic AMP accumulation rates, and they confirmed the diminished platelet cyclic AMP response in both schizophrenics and depressives, but this effect was confined to the platelets and could not be demonstrated in leucocyctes.

Prostaglandin F2 (PGF2) levels in a small sample of patients with affective disorder have been studied (Gross et al. 1977). They showed that lithium resulted in a small but significant elevation in plasma PGF levels. This increase was only apparent after one year and could not be detected in subjects who had only taken lithium for 12 weeks. The effect that psychotropic drugs have on the PGEl enhancement of adenyl cyclase and cyclic AMP production has attracted considerable interest because norepinephrine is a potent inhibitor of this enhancement (Murphy et al. 1973). Rotrosen (1980) showed that chloral hydrate and alcohol both increase this effect, but that most psychotropic drugs have little or no influence; they tested dopamine, propanolol, chlorpromazine, fluphenazine, haloperidol, promazine, thioridazine, imipramine, amitryptylene, benztropine, clozapine and morphine. Evidence that prostaglandins are involved in the functional psychoses is presently therefore somewhat scant, but we suggest here there may be a rather more compelling argument for implicating prostaglandins in NSAID induced lithium nephrotoxicity.

\section{NSAIDS, PSYCHOTROPIC DRUGS, THE KIDNEY AND PROSTAGLANDINS}

Certain drugs, but not others, seem to result in lithium induced nephrotoxicity, which in some cases may present clinically as lithium toxicity. Among the NSAIDs there seems to be good evidence that Piroxicam (Kerry et al. 1983; Walbridge \& Bazire, 1985; Nadarajah \& Stein, 1985) can do this. There are case reports that indomethacin (Hierschberg \& Sierles, 1983; Frolich et al. 1979; Reimann et al. 1983) and phenylbutazone (Imbs et al. 1978), but not ibuprofen (Walbridge \& Bazire, 1985) or aspirin (Bendz, 1983; Reimann et al. 1983), have been implicated. Piroxicam and indomethacin are highly potent inhibitors of prostaglandin synthesis, whereas ibuprofen and aspirin have roughly the same, and lower, potency in inhibiting prostaglandin synthesis (Flower et al. 1985). The mode of prostaglandin inhibition by indomethacin and aspirin is completely different, probably involving a different site on the enzyme cyclo-oxygenase (Flower et al. 1985). Considering the psychotropic drugs, there is a single case report of nephrotic syndrome arising from a combination of haloperidol and lithium (Moskovitz et al. 1981). In a more systematic study (Lassen et al. 1986) prochlorperazine, flupenthixol and haloperidol in combination with lithium caused a mild degree of polyuria, although clinical nephrotoxicity and lithium toxicity were not found to be documented with these combinations. On the other hand, in the same study tricyclic antidepressants in combination with lithium did not cause polyuria and had no affect on renal function. The action of chlorpromazine is more complex. In vitro, chlorpromazine is a potent inhibitor of prostaglandin synthesis, but in vivo chlorpromazine stimulates prolactin production and prolactin itself stimulates prostaglandin synthesis. Chlorpromazine tends to increase lithium clearance; Sletten et al. (1966) showed that a single oral dose of lithium was excreted more rapidly during chlorpromazine treatment.

The question therefore arises: are the psychotropic drugs which can also trigger lithium nephrotoxicity also the more potent prostaglandin synthetase inhibitors, as seems to be the pattern with the NSAIDs? To clarify this issue it would be most helpful to know exactly what various psychotropic drugs do to human renal prostaglandin synthetase activity, but such an investigation has not yet been undertaken. So far, the effect psychotropic drugs have on prostaglandin synthesis has only been studied in three animal preparations, namely rat brain (Schaeffer et al. 1978), bovine seminal vesicles (Krupp \& Wesp, 1975), and guinea-pig lung (Lee, 1974). The pattern of drug induced prostaglandin inhibition was quite different in these preparations, but this is consistent with the known marked variation in prostaglandin synthetase activity, both between different organs and between different species.

The profile of drugs which inhibit PG synthetase in the rat brain preparation (Schaeffer et al. 
1978) shows a remarkable similarity to the profile of drugs which can result in lithium-drug induced nephrotoxicity. In this preparation indomethacin produced $80 \%$ prostaglandin inhibition, promethazine $67 \%$, chlorpromazine $46 \%$, while aspirin produced only $32 \%$, desipramine $35 \%$, tranylcypromine $19 \%$, various monoamine oxidase inhibitors (MAOIs) such as pargyline and nialmide less than $10 \%$, and Ritalin $10 \%$. Drugs which had scores of greater than $40 \%$ inhibition in this preparation have been reported to give either lithium toxicity, or to result in a detectable alteration in renal function in lithium treated subjects. However, drugs with only a mild degree of PG inhibition scoring less than $40 \%$ in this preparation, such as aspirin, MAOIs, tricyclic antidepressants, and ritalin have never been associated with lithium induced nephrotoxity or alterations in renal function.

The pattern of PG synthetase inhibition that psychotropic drugs produced in the other two preparations was, however, rather different. In the bovine seminal visicle, chlorpromazine, desipramine and anafranil were all fairly potent PG inhibitors, whereas haloperidol was not. Because the lithium haloperidol combination is known to cause CNS toxicity (Cohen \& Cohen, 1974), it seems unlikely that CNS toxicity has a prostaglandin mediated mechanism. In the guineapig lung preparation (Lee, 1974) MAOIs such as phenelzine and tranylcypromine were very potent PG inhibitors, even more potent than indomethacin; whereas aspirin and chlorpromazine were very weak prostaglandin synthesis inhibitors, while the tricyclics, doxepin and desipramine provided an intermediate level of prostaglandin inhibition.

\section{CONCLUSIONS}

Toxic clinical interactions between lithium and NSAIDs are rare, and probably only occur in a small minority of instances when the two drugs are used together. They seem to occur in only two situations, first in association with the more potent NSAIDs such as Piroxicam, indomethacin and phenylbutazone, which are also very potent PG synthetase inhibitors and, secondly, among medically ill patients who may already have malfunctioning kidneys and who are often subjected to polypharmacy. Although rare, the interaction is of great theoretical interest since it suggests the possibility that when lithium nephrotoxicity occurs as a consequence of the administration of another drug, prostaglandin mechanisms may be involved. Evidence for this derives from the observations that only those NSAIDs which are highly potent prostaglandin synthesis inhibitors seem to result in this interaction, and that psychotropic drugs which interact with lithium in the kidney to produce polyuria also tend to be those drugs which are rather more powerful prostaglandin inhibitors. It is more likely that this effect is mediated by inhibiting the enzyme prostaglandin synthetase, since the profile of NSAID and psychotropic drugs that result in lithium toxicity seems to fit best the profile of prostaglandin synthetase inhibition in at least one animal preparation, namely, the rat brain. Furthermore, in one of the reported cases (Hierschberg \& Sierles, 1983) the patient was already taking a NSAID, namely Zomepirac, when the addition of a second NSAID indomethacin triggered off an episode of lithium toxicity. The effects which PGEl has on adenyl cyclase activity and on cyclic AMP production, and which have attracted much interest in psychiatric disorders, may be rather less important as the mediating mechanism, because most psychotropic drugs appear to have little influence on this reaction (Rotrosen et al. 1980).

New NSAIDs are being introduced into clinical practice at a rapid rate, and it would be very useful to have advanced knowledge of which drugs can produce this rare but potentially dangerous interaction. Imbs et al. (1979) have demonstrated in lithium treated mice that phenylbutazone, but not aspirin, resulted in an increased plasma lithium, a pattern resembling that found in humans. Possibly new NSAIDs should be screened using such animal models. Toxic clinical interactions are uncommon, but appear to be most significant for Piroxicam and indomethacin. These NSAIDs can still be used in conjunction with lithium, but it may be necessary to reduce lithium dosage and monitor plasma lithium levels a little more closely. Other NSAIDs seem to produce only relatively small increments in serum lithium, and unless the patients are also medically ill or on polypharmacotherapy little modification to routine serum lithium monitoring seems to be warranted. 


\section{REFERENCES}

Abdulla, Y. H. \& Hamadah, K. (1975). Effect of ADP on PGE formation in blood platelets from patients with depression, mania and schizophrenia. British Journal of Psychiatry 127, 591-595.

Amdisen, A. (1980). Monitoring lithium dose levels: clinical aspects of serum lithium estimation. In Handbook of Lithium Therapy (ed. F. N. Johnson), pp. 179-195. MTP Press: Lancaster.

Bendz, H. (1983). Kidney function in lithium treated patients. Acta Psychiatrica Scandinavica 68, 303-324.

Bendz, H. \& Feinberg, M. (1984). Aspirin increases serum lithium ion levels. Archives of General Psychiatry 41, 310-311.

Blackwell, B. (1976). Treatment adherence. British Journal of Psychiatry 129, 513-531.

Brezin, J. H., Katz, S. M., Schwartz, A. B., Chinitz, J. L. (1979). Reversible renal failure and nephrotic syndrome associated with nonsteroidal anti-inflammatory drugs. New England Journal of Medicine 301, 1271-1273.

Caldwell, H. C., Westlake, W. J., Connor, B. S. \& Flanagan, T. (1971). A pharmacokınetic analysis of lithium carbonate absorption from several formations in man. Journal of Clinical Pharmacology 11, 349-356.

Cohen, W. J. \& Cohen, N. H. (1974). Lithium carbonate haloperidol, and irreversible brain damage. Journal of the American Medical Association 230, 1283-1287.

Coppen, A., Bailey, J. E. \& White, S. G. (1969). Slow-release lithium carbonate. Journal of Clinical Pharmacology 9, 160-162.

Crammer, J. L., Rosser, R. M. \& Crane, G. (1974). Blood levels and management of lithium treatment. British Medical Journal ii, 650-654.

Donker, A. J. M., Arisz, L., Brentjens, J. R. H., Van der Hem, G. K. \& Hollemans, H. J. G. (1976). The effect of Indomethacin on kidney function and plasma renin activity in man. Nephron 17, 288-296.

Feldberg (1976). Possible association of schizophrenia with a disturbance in prostaglandin metabolism. A physiological hypothesis. Psychological Medicine 16, 359-369.

Flower, R. J., Moncada, S. \& Vane, J. R. (1985). Analgesicantipyretics and anti-inflammatory agents; drugs employed in the treatment of gout. In The Pharmacological Basis of Therapeutics, 7th edn (eds. G. Gilman, L. S. Goodman and T. W. Rall), pp. 674-715.

Frais, M. A., Burgess, E. D. \& Mitchell, L. B. (1983). Piroxicaminduced renal failure and hyperkalaemia. Annals of Internal Medicine 99, 129-130.

Frohlich, J. C., Leftwich, R., Ragheb, M., Oates, J. A., Reimann, I. \& Buchanan, D. (1979). Indomethacin increases plasma lithium. British Medical Journal i, 1115-1116.

Fry, D. E. \& Marks, V. (1971). Value of plasma-lithium monitoring. Lancel i, 886-888.

Galler, M., Folkert, V. W. \& Schlondorff, D. (1981). Reversible acute renal insufficiency and hyperkalaemia following indomethacin therapy. Journal of the Americal Medical Association 246, 154-155.

Gross, H. A., Dunner, D. L., La Fleur, D., Meltzer, H. \& Fieve, R. R. (1977). Prostaglandin $F$ in patients with affective disorder. Biological Psychiatry 12, 347-357.

Haghfelt, T., Lund, J. O. \& Jorgensen, H. E. (1971). Lithium forgiftning og nyrefunction. Nordisck Medicin 12, 1465-14711.

Hansen, H. E. \& Amdisen, A. (1978). Lithium intoxication (report of 23 cases and a review of 100 cases from the literature). Quarterly Journal of Medicine. New Series 47, 123-144.

Hansen, H. E., Hestbeck, J., Sorensen, J. L., Norgaard, K., Heilskov, J. \& Amdisen, A. (1979). Chronic interstitial nephropathy in patients on long-term lithium treatment. Quarterly Journal of Medicine 48, 577-591.

Hierschberg, S. N. and Sierles, F. S. (1983). Indomethacin induced lithium toxicity. American Family Physician 28 (2), 155-157.

Imbs, J. L., Danıon, J. M., Serban, M., Belhadi-Mostefa, M. \& Schmidt et Singer, L. (1978). Influence des anti-inflammatoires sur la réabsorption tubulaire du lithium. Journal of Pharmacology 9 , 171-172.
Kafka, M. S. and Van Kammen, D. P. \& Bunney, W. E. (1979). Reduced cyclic AMP in the blood platelets from schizophrenic patients. American Journal of Psychiatry 136, 685-687.

Kanof, P. D., Johns, C., Davidson, M., Siever, L., Coccaro, E. F. \& Davis, K. L. (1986). Prostaglandin sensitivity in psychiatric disorders. Archives of General Psychiatry 43, 987-993.

Kerry, R. J., Owen, G. \& Michaelson, S. (1983). Possible toxic interaction between lithium and piroxicam. Lancet $\mathrm{i}, 418-419$.

Kimberley, R. P., Bowden, R. E., Keiser, H. R. \& Plotz, P. H. (1978). Reduction of renal function by new non-steroidal antiinflammatory drugs. American Journal of Medicine 64, 804807.

Krupp, P. \& Wesp, . (1975). Psychotropic drugs and prostaglandin synthesis in bovine seminal vesicles. Experentia 31, 330.

Lassen, E., Vestergaard, P. \& Thomsen, K. (1986). Renal function of patients in long-term treatment with lithium cttrate alone or in combination with neuroleptics and antıdepressant drugs. Archives of General Psychiatry 43, 481-482.

Lee, R. E. (1974). Prostaglandin synthesis and psychotropic drugs in the guinea-pig lung. Prostaglandins 5, 63-00.

Leftwich, R., Walker, L. \& Smigel, M. (1977). Indomethacin is antidiuretic in lithium-induced diabetes insipidus. Clinical Research 25, 272A.

McCreadie, R. G. \& Morrison, D. P. (1985). The impact of lithium in south-west Scotland. I. Demographic and clinical findings. British Journal of Psychiatry 146, 70-80.

Moskovitz, R., Springer, P. \& Urquhart, M. (1981). Lithium-induced nephrotic syndrome. American Journal of Psychiatry 138, 382-383.

Mtabaji, J., Robinson, C. J., Mankum, M. S., Cronia D. \& Horrobin, D. F. (1977). Prostaglandin A2 at low infusion rates restores the anti-diuretic effect of vasopressin in lithium treated rats. Journal of Endocrinology 73, 31-36.

Murphy, D. L., Donnelly, C. \& Moskowitz, J. (1973). Inhibition by lithium of prostaglandin E1 and norepinephrine effects on cyclic adenosine monophosphate production in human platelets. Clinical Pharmacology and Therapeutics 14, 810-814.

Nadarajah, J. \& Stein, G.S. (1985). Piroxicam induced lithium toxicity. Annals of Rhetumatic Diseases 44, 502.

Overview (1986). Side effects of ant1-inflammatory drugs. An overview from the Second International Meeting, Queens College, Cambridge, 1985. Rheumatology in Practice 13-15.

Raftery, J., Forman, P., Farrington, K., Sweny, P. \& Moorhead, J. F. (1985). Fenclofenac induced interstitial nephritis confirmed by inadvertent rechallenge. British Medical Journal 290, 1178-1179.

Ragheb, M., Ban, T. A., Buchanan, D. \& Frohlich, J. C. (1980). Interaction of indomethacin and ibuprofen with lithium in manic patients under a steady state lithium level. Journal of Clinical Psychiatry 41, 397-398.

Reimann, I. W. \& Frohlich, J. C. (1981). Effects of diclofenac on lithium kinetics. Clinical Pharmacology and Therapeutics 30, 348-352.

Reimann, I. W., Diener, U. \& Frohlich, J. C. (1983). Indomethacin but not aspirin increases plasma lithium ion levels. Archives of General Psychiatry 40, 283-286.

Rotrosen, J., Miller A. D., Mandio, L. J., Trafficante, L. J. \& Gershon, S. (1980). Effects of ethanol and Prostaglandin El, biochemical and behavioural interactions. Life Sciences 26, 1867-1876.

Rotrosen, J., Miller, A. D., Mandio. L. D., Trafficante, L. J. \& Gershon, S. (1980). Prostaglandins, platelets and schizophrena. Archives of General Psychiatry 37, 1047-1064.

Schaeffer, A., Komlos, M. \& Seregi, A. (1978). Effects of biogenic amines and psychotropic drugs on endogenous prostaglandin biosynthesis in the rat brain homogenates. Biochemical Pharmacology 27, 213-218.

Shelley, R. K. (1986). Lithium and piroxicam. British Journal of Psychiatry 148, 343.

Sletten, I., Pichardo, J., Korol, B. \& Gershon, S. (1966). The effect of chlorpromazine on lithium excretion in psychiatric subjects. Current Therapeutic Research 8, 441-446.

Stokes, J. B. \& Kokko, J. P. (1977). Inhibition of sodium transport by prostaglandin $\mathrm{E} 2$ across the isolated perfused rabbit collecting tubule. Journal of Clinical Investigation 59, 1099-1104. 
Tan, S. R., Shapiro, R., Franco, R., Stockhard, H. \& Mulrow, P. J. (1979). Indomethacin-induced prostaglandin inhibition with hyperkalaemia: a reversible cause of hyporeninemic hypoaldosteronism. Annals of Internal Medicine 90, 783-785.

Tyrer, S., Hullin, R. P., Birch, N. J. \& Goodwin, J. C. (1976). Absorption of lithium following administration of slow-release and conventional preparations. Psychological Medicine 6, 51-58.

Vrhovac, B. (1984). Anti-inflammatory analgesics and drugs used in gout. In Meyler's Side Effect of Drugs, 10th edn (ed. M.N.G. Dukes), pp. 151-182. Elsevier: Amsterdam.

Walbridge, D. G. \& Bazire, S. R. (1985). An interaction between lithium carbonate and piroxicam presenting as lithium toxicity. British Journal of Psychiatry 147, 206-207.
Walker, R. G., Bennett, W. M., Davies, B. M. \& Kincaid Smith, P. (1982). Structural and functional effects of long term lithium therapy. Kidney International 21, Suppl. 11, 513-519.

Wang, Y. C., Pandey, G. N., Mendels, J. \& Frazer, A. (1974). Effect of prostaglandin El-stimulated adenylate cyclase activity of human platelets. Biochemical Pharmacology 23, 845-855.

Weir, J. G. (1973) Serum lithium estimations. British Medical Journal 1, 356-357.

Wendland, M. L., Wagoner, R. D., Hollay, K. E. (1980). Renal failure associated with fenoprofen. Mayo Clinic Proceedings 55, 103-107.

Wiseman, E. H. \& Boyle, J. A. (1980). Piroxicam (Feldene). Clinics in Rheumatic Diseases 6, 585-613. 